\title{
Genome-wide expression profiling reveals increased stability and mitochondrial energy metabolism of the human liver cell line HepaRG-CAR
}

\author{
Aziza A. A. Adam • Aldo Jongejan • Perry D. Moerland • Vincent A. van der Mark • \\ Ronald P. Oude Elferink $\cdot$ Robert A. F. M. Chamuleau $\cdot$ Ruurdtje Hoekstra $(\mathbb{C}$
}

Received: 25 November 2019/ Accepted: 24 February 2020/Published online: 4 March 2020

(C) The Author(s) 2020

\begin{abstract}
Human liver cell line HepaRG is a wellknown source of human hepatocyte-like cells which, however, displays limited biotransformation and a tendency to transform after 20 passages. The new HepaRG-CAR cell line overexpressing constitutive androstane receptor (CAR, NR1I3), a regulator of detoxification and energy metabolism outperforms the parental HepaRG cell line in various liver functions. To further characterize this cell line and assess its stability we compared HepaRG-CAR with HepaRG
\end{abstract}

Electronic supplementary material The online version of this article (https://doi.org/10.1007/s10616-020-00384-w) contains supplementary material, which is available to authorized users.

A. A. A. Adam - V. A. van der Mark .

R. P. Oude Elferink · R. A. F. M. Chamuleau .

R. Hoekstra $(\square)$

Tytgat Institute for Liver and Intestinal Research, AG\&M,

Amsterdam UMC, University of Amsterdam,

Meibergdreef 69-71, 1105 BK Amsterdam, The

Netherlands

e-mail: r.hoekstra@amc.uva.nl

A. A. A. Adam

e-mail: a.abdelrahmanabubakradam@amc.uva.nl

V. A. van der Mark

e-mail: rotarr@gmail.com

R. P. Oude Elferink

e-mail: r.p.oude-elferink@amc.uva.nl

R. A. F. M. Chamuleau

e-mail: r.a.chamuleau@amc.uva.nl cells at different passages for their expression profile, ammonia and lactate metabolism, bile acid and reactive oxygen species (ROS) production. Transcriptomic profiling of HepaRG-CAR vs. HepaRG earlypassage revealed downregulation of hypoxia, glycolysis and proliferation and upregulation of oxidative phosphorylation genesets. In addition CAR overexpression downregulated the mTORC1 signaling pathway, which, as mediator of proliferation and metabolic reprogramming, may play an important role in the establishment of the HepaRG-CAR phenotype. The ammonia and lactate metabolism and bile acid production of HepaRG-CAR cells was stable for 10 additional passages compared to HepaRG cells. Interestingly, bile acid production was 4.5 -fold higher in
A. Jongejan · P. D. Moerland
Department of Clinical Epidemiology, Biostatistics and Bioinformatics, Amsterdam UMC, University of
Amsterdam, Meibergdreef 9, 1105 AZ Amsterdam, The
Netherlands
e-mail: a.jongejan@amc.uva.nl
P. D. Moerland
e-mail: p.d.moerland@amc.uva.nl
V. A. van der Mark · R. Hoekstra
Surgical Laboratory, Amsterdam UMC, University of Amsterdam, Meibergdreef 9, 1105 AZ Amsterdam, The Netherlands 
HepaRG-CAR vs. HepaRG cells, whereas lactate and ROS production were 2.7- and 2.0-fold lower, respectively. Principal component analysis showed clustering of HepaRG-CAR (early- and late-passage) and HepaRG early-passage and not with HepaRG latepassage indicating that passaging exerted larger effect on the transcriptional profile of HepaRG than HepaRG-CAR cells. In conclusion, overexpression of CAR in HepaRG cells improves their bile acid production, mitochondrial energy metabolism, and stability, with the latter possibly due to reduced ROS production, resulting in an optimized source of human hepatocytes.

Keywords Constitutive androstane receptor . Dedifferentiation · Mitochondrial energy metabolism · Oxidative stress

\section{Background}

Highly differentiated human hepatocytes from proliferative sources are needed for hepatocyte-based in vitro models of human liver and for several clinical applications, such as Bio-artificial Livers (BALs). Yet, at present, hepatocytes deriving from different proliferative sources, as stem cells, induced pluripotent stem cells and liver cell lines, are lacking complex hepatic functions (van Wenum at al. 2014), and mature primary human hepatocytes (PHHs) are scarce and costly. The human liver cell line HepaRG displays a relatively high hepatic functionality and its transcriptome profile resembles that of PHHs most closely compared to other proliferative sources of human hepatocytes (Gao and Liu 2017; Kvist et al. 2018). During culturing, HepaRG cells progress in a period of 4 weeks from progenitor cells into a mixed population of hepatocyte-islands surrounded by cholangiocytelike cells (Gripon et al. 2002). In our lab, we successfully applied the HepaRG cell line as a biocomponent of the AMC-BAL in an animal study (Nibourg et al. 2012). However, one of the major obstacles that limit the usage of HepaRG cells, is their tendency to transform after undergoing 20 passages from isolation with a split ratio of 1:5. The HepaRG cells then gradually lose their hepatic differentiation and acquire a mesenchymal phenotype with glycolysis-dependent energy metabolism, as evidenced by increased lactate production (Laurent et al. 2013; Adam et al. 2018a). This instability represents a hurdle towards the long-term and large-scale usage of HepaRG cells, as required for BAL application. In addition, the biotransformation properties, also deemed essential for BAL application, although higher compared to other proliferative sources of human hepatocytes, are, in part, still limited in absence of dimethylsulfoxide (DMSO) (Kvist et al. 2018; Andersson et al. 2012; Hoekstra et al. 2013). DMSO treatment increases biotransformation, but negatively affects cell viability and transcript levels of hepatic genes unrelated to biotransformation (Hoekstra et al. 2011). Moreover, for pharmacological applications, the HepaRG cells still prove insufficient in predicting liver-induced toxicity (Sison-Young et al. 2017; Bell et al. 2017). To improve biotransformation properties without DMSO treatment, we recently established a new stable cell line, HepaRG-CAR, by lentiviral overexpression of the constitutive androstane receptor (CAR, NR1I3) in HepaRG cells (van der Mark et al. 2017). CAR is a transcription factor involved in drug metabolism, but also in other processes, including energy metabolism, lipid homeostasis and cell proliferation (Yan et al. 2015). The resulting HepaRG-CAR cells exhibited increased biotransformation, including cytochrome P450 (CYP) activities and bilirubin conjugation. In addition, also albumin production, resistance to DMSO-induced toxicity, and $\mathrm{NAD}(\mathrm{P}) \mathrm{H}$ levels were elevated by CAR overexpression, however ammonia elimination remained unchanged (van der Mark et al. 2017).

To further investigate its potential as proliferative hepatocyte source we compared the transcriptional profile of the newly established HepaRG-CAR cell line and its parental cell line HepaRG using next generation RNA sequencing (RNA-seq) and assessed their stability upon serial passaging.

\section{Materials and methods}

Cell culture

HepaRG cells were kindly provided by Biopredic International (Rennes, France). The HepaRG-CAR line was developed by stable lentiviral overexpression of the nuclear receptor CAR, as described (van der Mark et al. 2017). This cell line is designated as 
HepaRG-CAR (RRID:CVCL_X149) in Cellosaurus (Bairoch 2018), and could be considered as a constituent of the human hepatocyte invitrome, which would be all the human liver cells expressing hepatocyte properties (Bols et al. 2017). HepaRG and HepaRG-CAR cells were maintained in William's E-based culture medium (HepaRG medium) in a humidized atmosphere of $95 \%$ air and $5 \% \mathrm{CO}_{2}$., as described (Gripon et al. 2002; Hoekstra et al. 2011), and the medium was refreshed twice/week. To test the stability of the cells upon serial passaging, the cultures were propagated starting at passage 15 (P15) for HepaRG and P19 for HepaRG-CAR from isolation. The cultures were passaged at a regular 1:5 ratio once per 2 weeks, and for every two passages (passage 15, $17,19,21,23,25,27,29$ and 31) cells were seeded in parallel in 12-well culture plates for testing functionality and obtaining RNA after 4 weeks culturing.

\section{RNA isolation}

PHHs were isolated from the healthy parenchyma in liver resection material from three caucasian patients, aged 40-68 (Table 1 for details), with no macroscopic signs of liver damage, by a modified 2-step collagenase perfusion technique, as described (Hoekstra et al. 2006). Cells were snap-frozen directly after isolation and kept in liquid nitrogen until RNA isolation. The procedure was in accordance with the ethical standards of the institutional committee on human experimentation (Medical Ethical Committee of the Academic Medical Center, University of Amsterdam, protocol number 03/024) and the Helsinki Declaration of 1975 and after obtaining written informed consent. Total RNA was isolated using the RNeasy kit (QIAGEN) from the three PHH isolates and 12 samples of fully differentiated cultures, including three samples from HepaRG early-passage cultures (P15 and P16), three HepaRG late-passage cultures (P21), three HepaRG-CAR early-passage cultures (P17) and three HepaRG-CAR late-passage cultures (P22), for more information refer to Table 1. The quality of the RNA was assessed by Agilent RNA 6000 Nano-Bioanalyzer. Samples with RNA integrity number above 7 were used for RNA-seq (all samples).
cDNA preparation and RNA-seq

A cDNA library was prepared from ribosomaldepleted RNA (50 ng input/sample) according to the Ovation ${ }^{\circledR}$ RNA-Seq System V2 kit (Nugen) protocol. Next, the cDNA was fragmented, blunt ended, ligated to indexed (barcoded) adaptors and amplified with PCR using the Ovation ${ }^{\circledR}$ Ultralow System V2 kit (Nugen) according to manufacturer's protocol. Prior to RNA-seq analysis, the final library size distribution was determined using Agilent Bioanalyzer 2100. Fifteen cDNA libraries were prepared with one library per RNA sample. Next, all cDNA libraries were pooled and single-end sequenced (50 nucleotides) on two lanes of the Illumina HiSeq4000 platform.

RNA sequencing data analysis

Raw sequencing data were subjected to quality control using FastQC and trimmed using Trimmomatic (v0.32). Reads were aligned to the human reference genome (hg38) using HISAT2 (v2.0.4). Gene level counts were obtained using HTSeq (v0.6.1) and the human GTF (gene transfer format) file from Ensembl (release 85). Samples from a different well, but from the same cell line, seeded from the same culture were considered to be technical replicates and their counts were summed, therefore ( $\mathrm{n}=1$ or 2 )/group, refer to Online Resource 1. One of the PHHs sample was excluded, as it clearly exhibited a cancerous rather than hepatic transcriptional profile. Based on principal component analysis (PCA), one of the HepaRG-CAR late samples was identified as outlier and therefore excluded from downstream analysis. Statistical analyses were performed using the edge R and limma $\mathrm{R}$ (v.3.4.1) and Bioconductor (v3.5) packages. Genes with more than one count in one or more samples were retained. The two most abundant genes (MT-RNR1 and MT-RNR2) were removed in order to stabilize the scaling factors. Count data were transformed to $\log 2-$ counts per million ( $\log \mathrm{CPM})$, normalized by calculating scaling factors using the trimmed mean of M-values method and precision weighted using voom. Differential expression was assessed using an empirical Bayes moderated t-test within limma's linear 
Table 1 Details of the isolated PHHs and monolayer cultures used for the RNA-seq analysis

\begin{tabular}{lllll}
\hline Sample & Culture line & Passage & ID & Exonic reads \\
\hline HepaRG & BB & P15 & HepaRG early-passage, replicate 1 & $14,004,119$ \\
HepaRG & BG & P16 & HepaRG early-passage, replicate 2 & $16,656,149$ \\
HepaRG & BG & P16 & HepaRG early-passage, replicate 2 & $14,602,082$ \\
HepaRG & BB & P21 & HepaRG late-passage, replicate 1 \\
HepaRG & BB & P21 & HepaRG late-passage, replicate 1 & $12,419,838$ \\
HepaRG & BG & P21 & HepaRG late-passage, replicate 2 & $12,168,126$ \\
HepaRG-CAR & A & P17 & HepaRG-CAR early-passage, replicate 1 & $15,193,830$ \\
HepaRG-CAR & A & P17 & HepaRG-CAR early-passage, replicate 1 & $12,122,156$ \\
HepaRG-CAR & A & P17 & HepaRG-CAR early-passage, replicate 1 & $11,506,605$ \\
HepaRG-CAR & A & P22 & HepaRG-CAR late-passage, replicate 1 (excluded) & $11,285,599$ \\
HepaRG-CAR & A & P22 & HepaRG-CAR late-passage, replicate 1 & $13,325,420$ \\
HepaRG-CAR & C & P22 & HepaRG-CAR late-passage, replicate 2 & $13,483,596$ \\
PHHs 1 & NA & Fresh isolate & PHHs 1 (excluded). Donor: male, 68 years, liver metastasis \\
PHHs 2 & NA & Fresh isolate & PHHs 2. Donor: female, 40 years, intraductular papilloma of & $14,750,007$ \\
PHHs 3 & NA & Fresh isolate & PHHs 3. Donor: female, 41 years, adenoma & $14,744,261$ \\
\hline
\end{tabular}

In this table the culture line and passage number of HepaRG and HepaRG-CAR cultures are given, together with the new ID of the replicates and total number of exonic reads per sample (after filtering)

NA not applicable

model framework including the precision weights estimated by voom. Resulting $P$-values were corrected for multiple testing using the Benjamini-Hochberg false discovery rate (FDR). Additional gene annotation was retrieved from Ensembl (release 91) using the biomaRt R/Bioconductor package. PCA was performed on the $\log C \mathrm{PM}$ values of the 5000 most variable genes (function prcomp). The variance explained by the first two principal components was calculated as percentage of the total variance. Geneset enrichment analysis was performed using CAMERA (limma package) with preset value of 0.01 for the inter-gene correlation using the Hallmark, C1, C2, C3, C5, C6 and C7 geneset collections retrieved from the Molecular Signatures Database (v6.0; Entrez Gene ID version. $P$-values were calculated for each geneset for two alternative hypotheses ('up' or 'down') and adjusted using the Benjamini-Hochberg FDR. Geneset variation analysis (GSVA) was performed using the GSVA package. Sample-specific geneset enrichment scores calculated by GSVA were clustered using Euclidean distance and complete linkage as agglomeration method (function hclust).
Quantitative reverse transcription PCR (RTqPCR)

Quantitative RT-PCR was performed as previously described (Hoekstra et al. 2005; Nibourg et al. 2013). Transcript levels were normalized for $18 \mathrm{~S}$ ribosomal RNA and expressed as a \% of the average of two human liver samples. Primer sequences and amplicon sizes are given in Table 2.

Hepatic function test

HepaRG and HepaRG-CAR fully-differentiated monolayer cultures of different passages were tested in 12-well plates (Corning) for their functionality, as described (Chiang 2009). Briefly, cultures were exposed to $1.5 \mathrm{~mL}$ test medium based on HepaRG medium supplemented with $1 \mathrm{mM}$ carbamoyl glutamate, the allosteric activator of the urea cycle enzyme carbamoyl phosphate synthase $1,1.5 \mathrm{mM} \mathrm{NH}_{4} \mathrm{Cl}, 2.27$ $\mathrm{mM}$ D-galactose, $2 \mathrm{mM}$ L-lactate and $125 \mu \mathrm{M}$ testosterone (all compounds from Sigma Aldrich). During 
Table 2 Primers used in PCR analyses and amplicon size

\begin{tabular}{llll}
\hline Gene & Sense sequence & Anti-sense sequence & Size bp \\
\hline $18 S$ rRNA & TTCGGAACTGAGGCCATGAT & CGAACCTCCGACTTTCGTTCT & 151 \\
$C A T$ & TGGGATCTCGTTGGAAATAACAC & TCAGGACGTAGGCTCCAGAAG & 146 \\
SOD1 & GGTGGGCCAAAGGATGAAGAG & CCACAAGCCAAACGACTTCC & 227 \\
SOD2 & TTTCAATAAGGAACGGGGACAC & GTGCTCCCACACATCAATCC & 109 \\
\hline
\end{tabular}

the function test, medium samples were taken at $0.75 \mathrm{~h}$ $(0.5 \mathrm{~mL})$ and at $24 \mathrm{~h}$ in which L-lactate, ammonia and bile acids were measured, as described (Adam et al. 2018a). At termination, the cells were washed with phosphate buffered saline and total protein/well was determined, as described (Adam et al. 2018a). Metabolic activities were calculated on basis of the changes in concentration in medium in time, normalized to the protein content per well (function test rawdata is given in Online Resource 1).

\section{Mitochondrial superoxide detection (MitoSOX)}

MitoSOX based flow cytometric assay was used to detect mitochondrial superoxide in 4-week cultures of low-passage HepaRG and HepaRG-CAR cells in 24-well plates. MitoSOX targets to mitochondria, where oxidation by superoxide results into red fluorescence (Zhou et al. 2011). The cells were incubated with $250 \mu \mathrm{L}$ of Hanks' balanced salt solution (Gibco) containing $10 \mathrm{mM}$ HEPES (pH7.4, Sigma) and $5 \mu \mathrm{M}$ freshly prepared MitoSOX (Thermo Fisher) for $0.5 \mathrm{~h}$. Subsequently, the cells were trypsinized and fluorescence was analyzed by flow cytometry, data of MitoSox analysis is shown in Online Resource 1.

\section{Statistical analysis}

We performed one-way ANOVA test with Dunnett's post hoc test to compare the mean of the baseline passage of either HepaRG (P15) or HepaRG-CAR (P19) with the mean of every other passage analyzed within the same cell line. Furthermore, Student's $t$-test was applied to compare the corresponding passages (P19-P25) in HepaRG vs. HepaRG-CAR. Analyses were performed with Prism version 7 (GraphPad Prism Inc). Data are expressed as mean $\pm \mathrm{SD}$; $P$ value $<0.05$ was considered as significant.

\section{Results}

HepaRG-CAR cell line exhibits more stable hepatic functionality upon passaging

To compare the stability of the HepaRG and HepaRGCAR cell lines, the cultures were passaged every 2 weeks, and their hepatic functionality was assessed once every two passages.

HepaRG cultures showed gradual morphological changes over passaging. At early passage (P15) the cultures displayed well-delineated hepatocyte-islands surrounded by flat cholangiocyte-like cells (Fig. 1a). The island structure was partially maintained after five passages (P20) (Fig. 1b), and was totally disrupted at P25 (Fig. 1c), and the cell size was reduced. In contrast, the island structure of HepaRG-CAR cultures showed no evident changes up to P30 (Fig. 1d-f), indicating increased morphological stability upon serial passaging at least up to 10 passages above the critical passage P20 of HepaRG cells.

Furthermore, we compared functionality and total protein content of HepaRG and HepaRG-CAR monolayers upon passaging, refer to Online Resource 1. Total protein content/well exhibited an increasing trend in both cell lines upon passaging (Fig. 1g). At $\mathrm{P} 25$, the total protein content was 1.6-fold higher in HepaRG vs. HepaRG-CAR cells. At late passages (P27-P31), the total protein content/well was significantly increased in the HepaRG-CAR line compared to baseline level. Ammonia elimination, which is a hepatocyte hallmark function, severely deteriorated with the passaging of HepaRG cells and converted into marginal ammonia production at P25 (Fig. 1h). In contrast, ammonia elimination by HepaRG-CAR cells displayed more stable profile through all tested passages, except for P21 which was 2.1-fold improved 

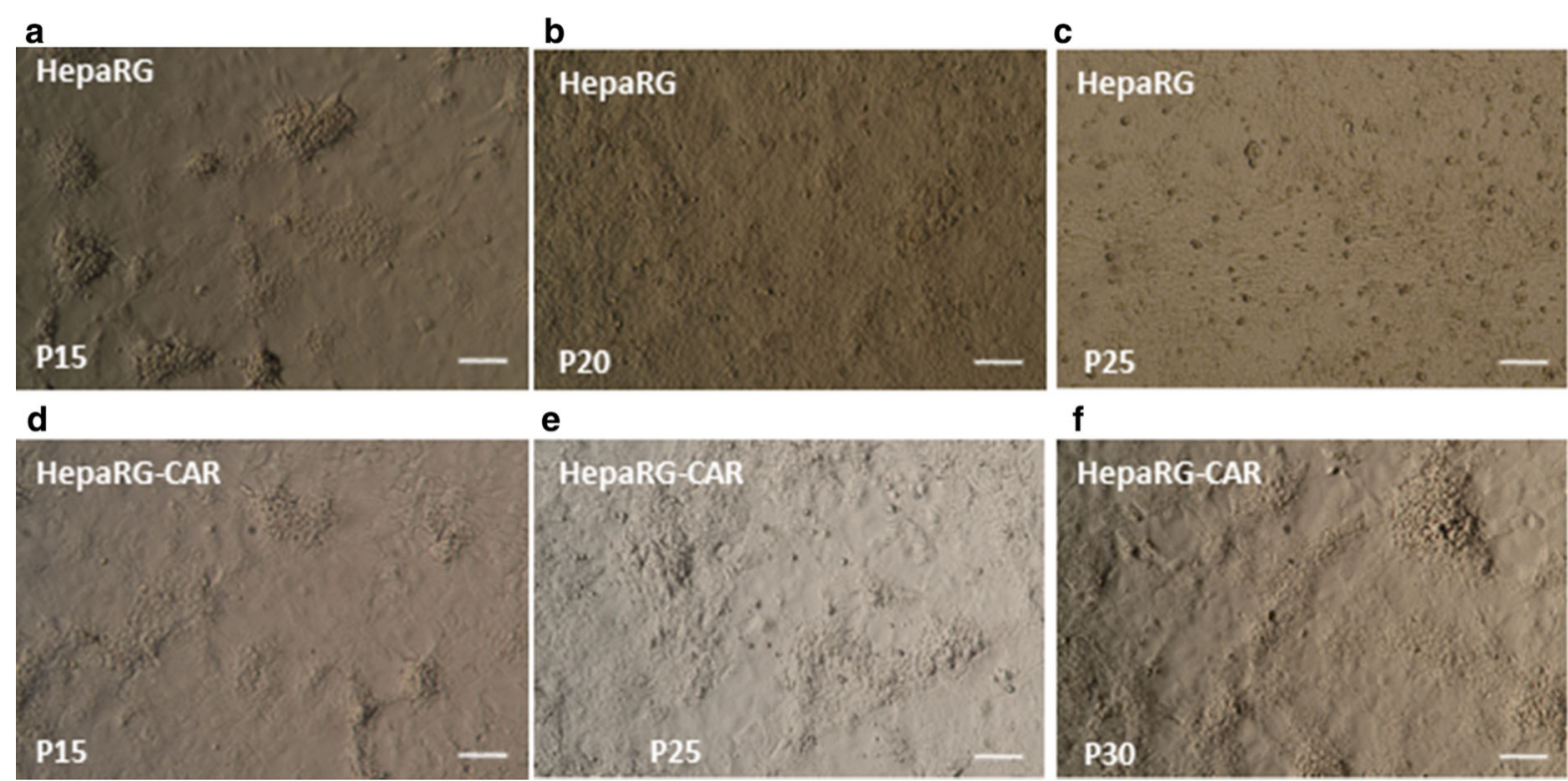

e

f
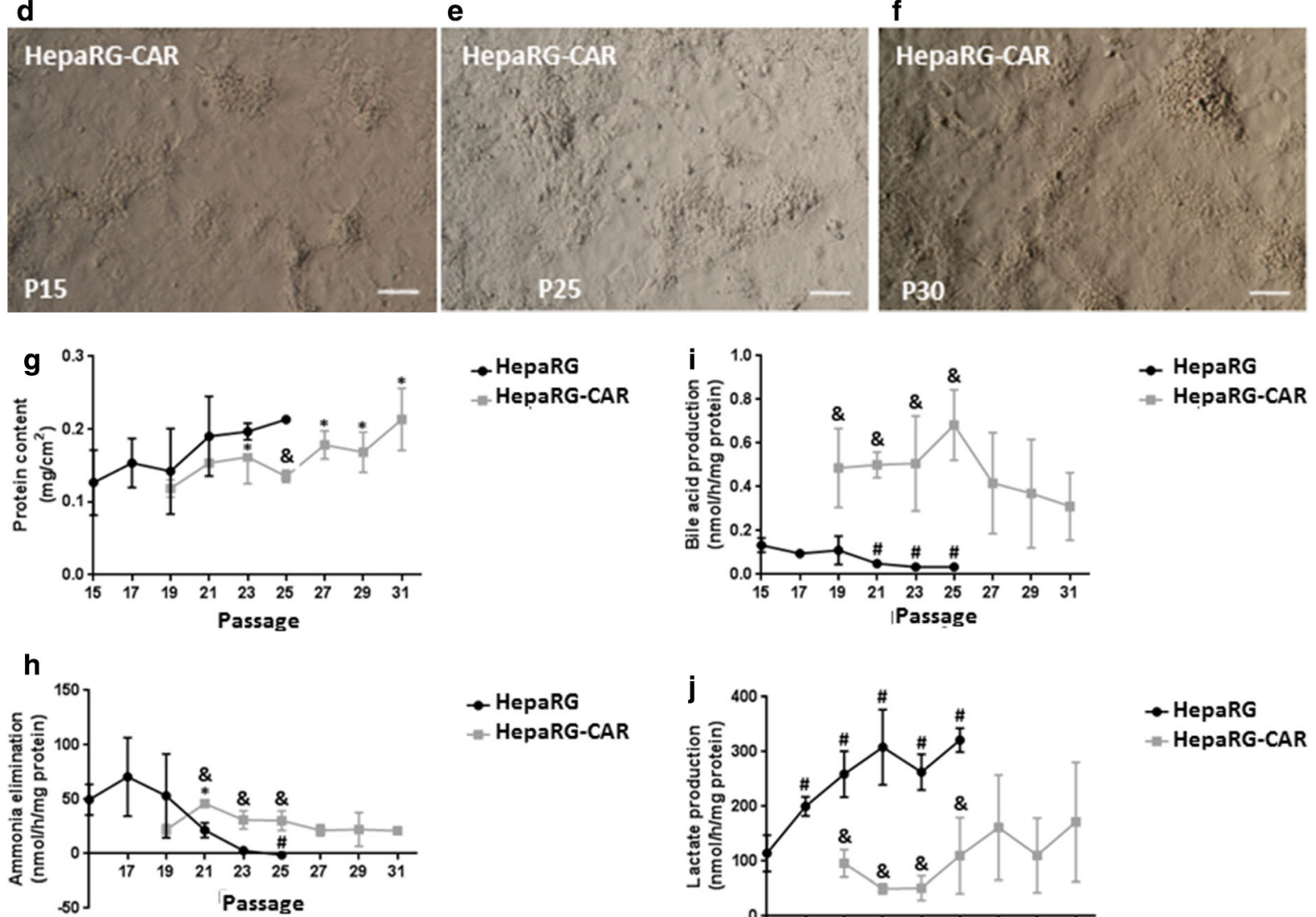

Fig. 1 HepaRG-CAR morphology and functions are more stable upon passaging. a-f Morphology. Scale bar $=100 \mu \mathrm{M}$. g Protein content/well. h Ammonia elimination. i Lactate

vs. baseline (P19) level. Notably, ammonia elimination by HepaRG-CAR cells was exceeding the level of HepaRG cells starting from P21. Similarly, bile acid synthesis, another essential hepatocyte function, declined 3.9-fold during the passaging of HepaRG cells from P15 until P25 (Fig. 1i) and was stable in HepaRG-CAR cells. In addition, bile acid synthesis

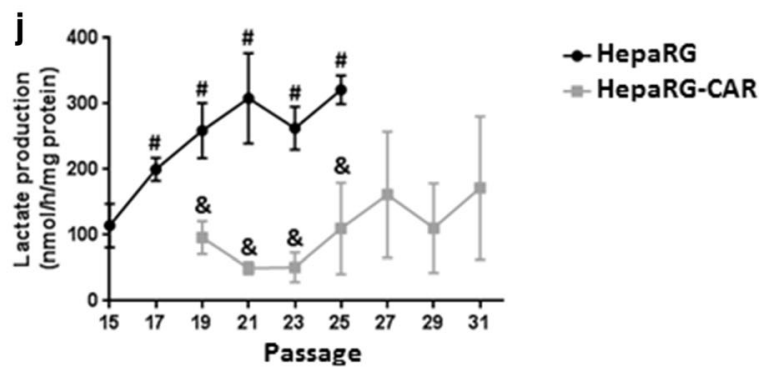

production. $\mathbf{j}$ Bile acid production, $(\mathrm{n}=3-9 / 1-3$ independent experiments). Significance is indicated by ${ }^{\#}$ vs. HepaRG P15,

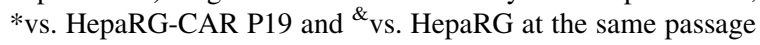

was 4.5-fold higher in HepaRG-CAR cells vs. HepaRG cells at P19. For comparison, the average ammonia elimination and bile acid production of the HepaRG-CAR cells at P19-P31 were 29\% and 31\% the levels found in PHHs (Hoekstra et al. 2011, 2013). Lactate production, as a measure of mitochondrial dysfunction, raised gradually in HepaRG cells up to 
2.8-fold difference at P25 vs. P15 (Fig. 1j). Again, HepaRG-CAR cells exhibited a stable lactate production during passaging. At P19 the lactate production in HepaRG-CAR cells was 2.7-fold lower when compared to P19 HepaRG cultures, suggesting that HepaRG-CAR cells possess an enhanced and sustainable mitochondrial function, although still not at the level of PHHs that actually eliminate lactate.

Collectively, these results show that HepaRG cultures lose their hepatic functionality upon passaging whereas HepaRG-CAR cells display a stable phenotype for 10 passages above the critical P20 in the parental cells and also show improved basal bile acid production and lactate metabolism, whereas ammonia clearance was comparable to HepaRG cells.

The effect of passaging on the transcriptional profile of HepaRG-CAR cells is limited

To investigate the molecular background of the increased hepatic differentiation and stability of HepaRG-CAR cells, RNA-seq was performed of the HepaRG and HepaRG-CAR fully differentiated cultures at different passages (early, i.e. P15-P17 vs. late, i.e. P21-P22) and their gene expression profiles were compared with those of two PHH isolates that served as gold standard. PCA revealed that the expression profiles of HepaRG and HepaRG-CAR cells, regardless of the passage number, were different from those of PHHs (Fig. 2a). Interestingly, expression profiles of HepaRG-CAR (early- and late-passages) cells were similar and clustered to some extent with those of the HepaRG early-passage cells, and deviated considerably from those of HepaRG late-passage cells (Fig. 2a).

Next, we identified differentially expressed genes (DEGs) between HepaRG and HepaRG-CAR cells. There were 171 upregulated genes and 209 downregulated genes between HepaRG vs. HepaRG-CAR at early-passage (Fig. 2b). Analysis of DEGs as a measure of the passaging effect on gene expression, revealed far less changes in HepaRG-CAR late- vs. early-passage with only 93 upregulated and 344 downregulated genes, compared to HepaRG late- vs. early-passage with 870 and 929 genes up- and downregulated respectively (Fig. 2b).
Upon passaging, the transcriptional profile of HepaRG cells shifts towards dedifferentiation and cell proliferation with enhanced hypoxia

Geneset enrichment analysis was employed to identify genesets enriched in DEGs. The Hallmark genesets that include 50 genesets derived from the Molecular Signature Database (MSigDB) (Liberzon et al. 2015), and the HSIAO liver-specific geneset, which contains 238 liver-specific genes (Hsiao et al. 2001), in more detail, were employed to assess different biological processes and hepatic differentiation, resp.. Furthermore, we visualized the relatedness of the different groups for ten selected discriminative genesets involved in energy metabolism, hepatic differentiation and cell proliferation in a heatmap (Fig. 3, for better resolution image, refer to Online Resource 7). These genesets were selected from differentially regulated Hallmark genesets of early- and late-passages from both HepaRG and HepaRG-CAR cells and PHHs. Among the top 19 differentially regulated (FDR $<$ $0.1)$ genesets, there were 18 upregulated genesets and only one geneset that was downregulated in HepaRG early-passage vs. HepaRG-CAR early-passage, (Table 3, for the complete gene-set analysis, refer to Online Resource 2). Among the upregulated genesets, six genesets were related to cell proliferation and four genesets were involved in inflammatory response. Interestingly, hypoxia and glycolysis Hallmark genesets were upregulated, whereas oxidative phosphorylation (OxPhos) was downregulated in HepaRG earlypassage vs. HepaRG-CAR early-passage (Fig. 3, Online Resource 7). This, together with the relatively high lactate production suggests that HepaRG cells highly depend on glycolysis to obtain their energy, whereas HepaRG-CAR cells are more dependent on mitochondrial energy metabolism. Despite the improvement of some hepatic functions (albumin synthesis, bile acid synthesis, lactate metabolism, and, in part, biotransformation) (Catapano et al. 1996), neither the HSIAO liver-specific geneset (FDR = 0.41), nor Hallmark genesets related to hepatic functions were overrepresented in early passages of HepaRG-CAR vs. HepaRG cells. 


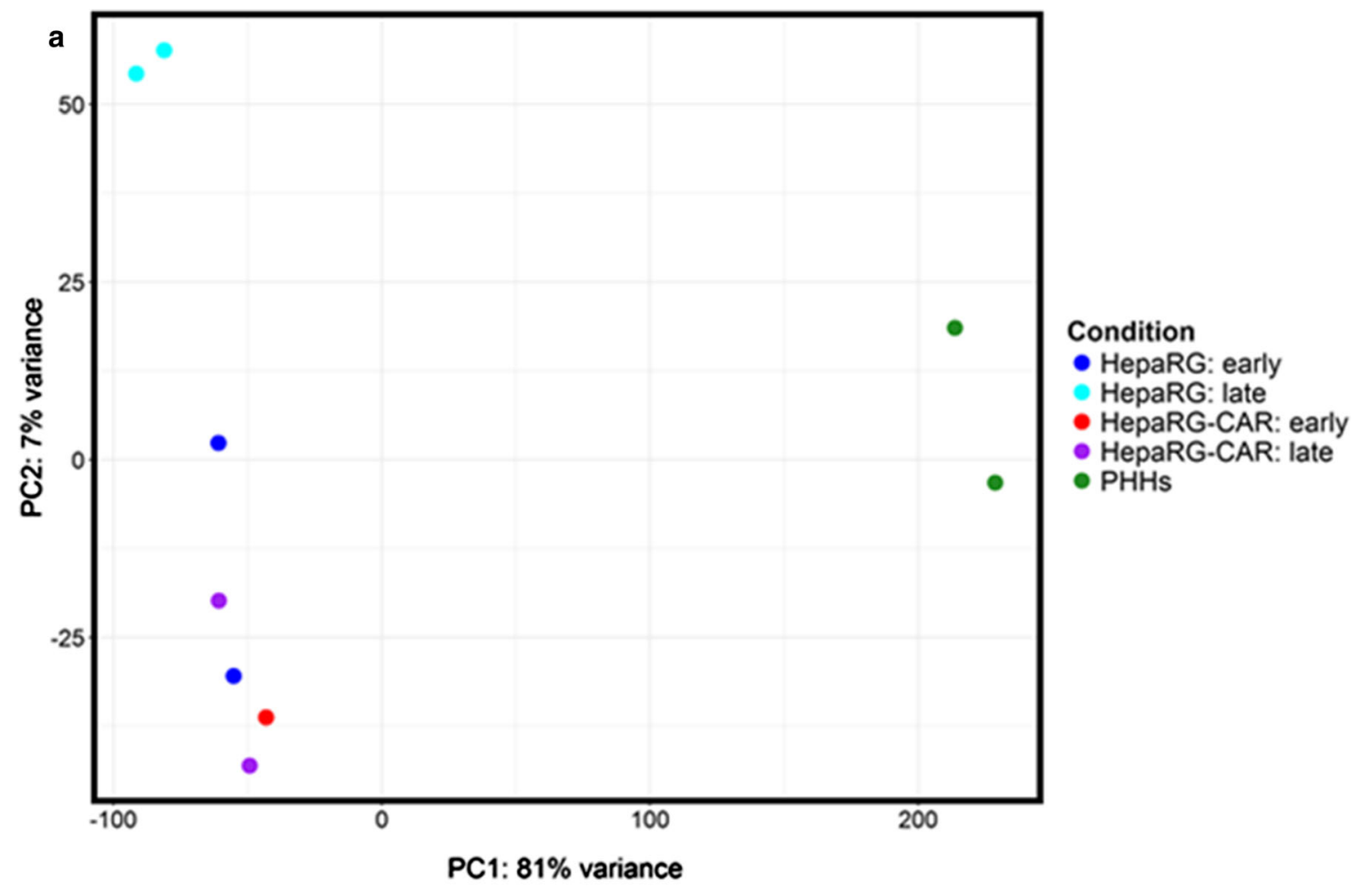

b

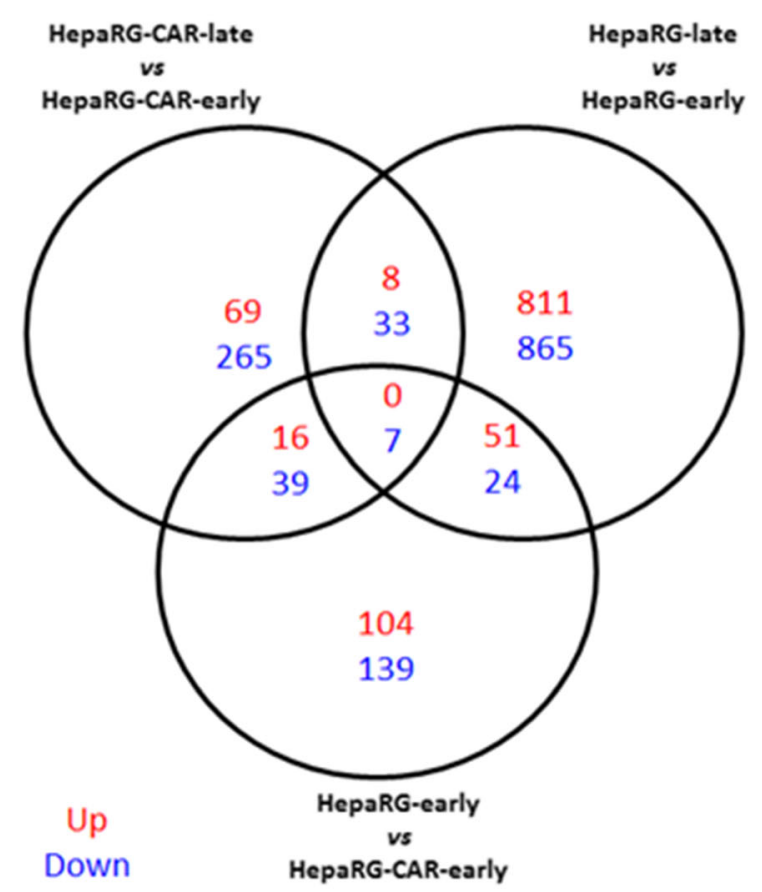

$P$ value $=0.01$ (none) 
4Fig. 2 The effect of passaging on the transcriptome of the HepaRG-CAR cell line is limited. a Principal component analysis of gene expression data. Each symbol represents an individual sample. PC1 and PC2 indicate principal components 1 and 2. b Venn diagram of DEG, cut-off $P$-value 0.01 (not adjusted). Numbers shown in the center of the Venn diagram represent the significantly upregulated (up) and downregulated (down) DEG. The total number of up- and downregulated genes included in the analysis is depicted in the lower right corner. (Color figure online)

Furthermore, to assess the degree of hepatic and metabolic competence of HepaRG cells, we compared the transcriptional profile of HepaRG early-passage to that of PHHs. In the top 20 differentially regulated genesets, 15 and five genesets were up- and downregulated, resp. (Table 4, for the complete gene-set analysis refer to Online Resource 3). Nine of the 15 upregulated genesets were involved in cell proliferation. Other upregulated genesets appearing in the top 20 list were related to unfolded protein response, protein secretion and UV response. The five downregulated genesets were all associated to liver functions, including the HSIAO liver-specific geneset, the xenobiotic detoxification, fatty acid oxidation, bile acid metabolism and coagulation genesets. This outcome indicates the lower hepatic differentiation grade of HepaRG cells compared to PHHs.

The top 20 differentially regulated genesets in HepaRG-CAR early-passage vs. PHHs was highly similar to that of the HepaRG early-passage vs. PHH comparison with 15 upregulated genesets including nine related to cell proliferation and the same five downregulated genesets (Table 4). In line with the observation that HepaRG-CAR cells show relatively high lactate metabolism, the OxPhos was more induced in HepaRG-CAR early-passage than in PHHs (Table 5-for the complete gene-set analysis refer to Online Resource 4 and Fig. 3 and Online Resource 7), however, it should be noted that PHHs replicates displayed a variable OxPhos profile, which complicates the interpretation of the heatmap (Fig. 3, Online Resource 7). In brief, these data show that the hepatic differentiation of HepaRG-CAR cells is also still underdeveloped when compared to PHHs.
To study the effect of passaging on the transcriptional profile of HepaRG and HepaRG-CAR cells, we compared the transcriptional profile of the Hallmark genesets and HSIAO liver specific-geneset of earlypassage to that of late-passage within the same cell line.

In HepaRG late-passage vs. HepaRG early-passage, only 16 differentially regulated genesets, with FDR $<0.1$, were identified, including five upregulated and 11 downregulated genesets (Table 6, for the complete gene-set analysis refer to Online Resource 5). Three of the upregulated Hallmark genesets were linked to cell cycle and proliferation (3/5), in agreement with the trend of increased protein synthesis at late passages. The same liver function-associated genesets differentially regulated between early passages of HepaRG and HepaRG-CAR vs. PHHs were downregulated in the top differentially regulated genesets of HepaRG late- vs. HepaRG early-passage, indicating loss of hepatic differentiation upon passaging of HepaRG cells, which was further confirmed by upregulation of the epithelial-mesenchymal transition geneset. In line with increased lactate production upon passaging, the bioenergetics profile of HepaRG cells was shifted to suppression of OxPhos and induction of hypoxia related genesets. The shift in energy metabolism by decreasing the OxPhos activity was further reflected by the downregulation of the geneset related to reactive oxygen species (ROS), (Fig. 3, Online Resource 7). Furthermore, two immunity-related, interferon-response genesets were downregulated upon passaging of HepaRG.

There were only eight differentially regulated genesets in HepaRG-CAR late-passage vs. HepaRGCAR early-passage of which six were upregulated and two downregulated (Table 7, for the complete gene-set analysis refer to Online Resource 6). All of the six upregulated genesets were related to cell proliferation, compatible with the increased protein synthesis at later passage. Interestingly, upon passaging of HepaRGCAR cells the Hallmark geneset epithelial mesenchymal transition was downregulated, and there was no effect on hepatic differentiation as the transcriptional profile of the HSIAO liver-specific-geneset was not significantly altered (FDR $=0.43$ ), and none of the genesets associated to hepatic functions appeared in the top differentially regulated genesets. In addition, the angiogenesis process, which is critically important for cancer cells to meet their increasing demand for 


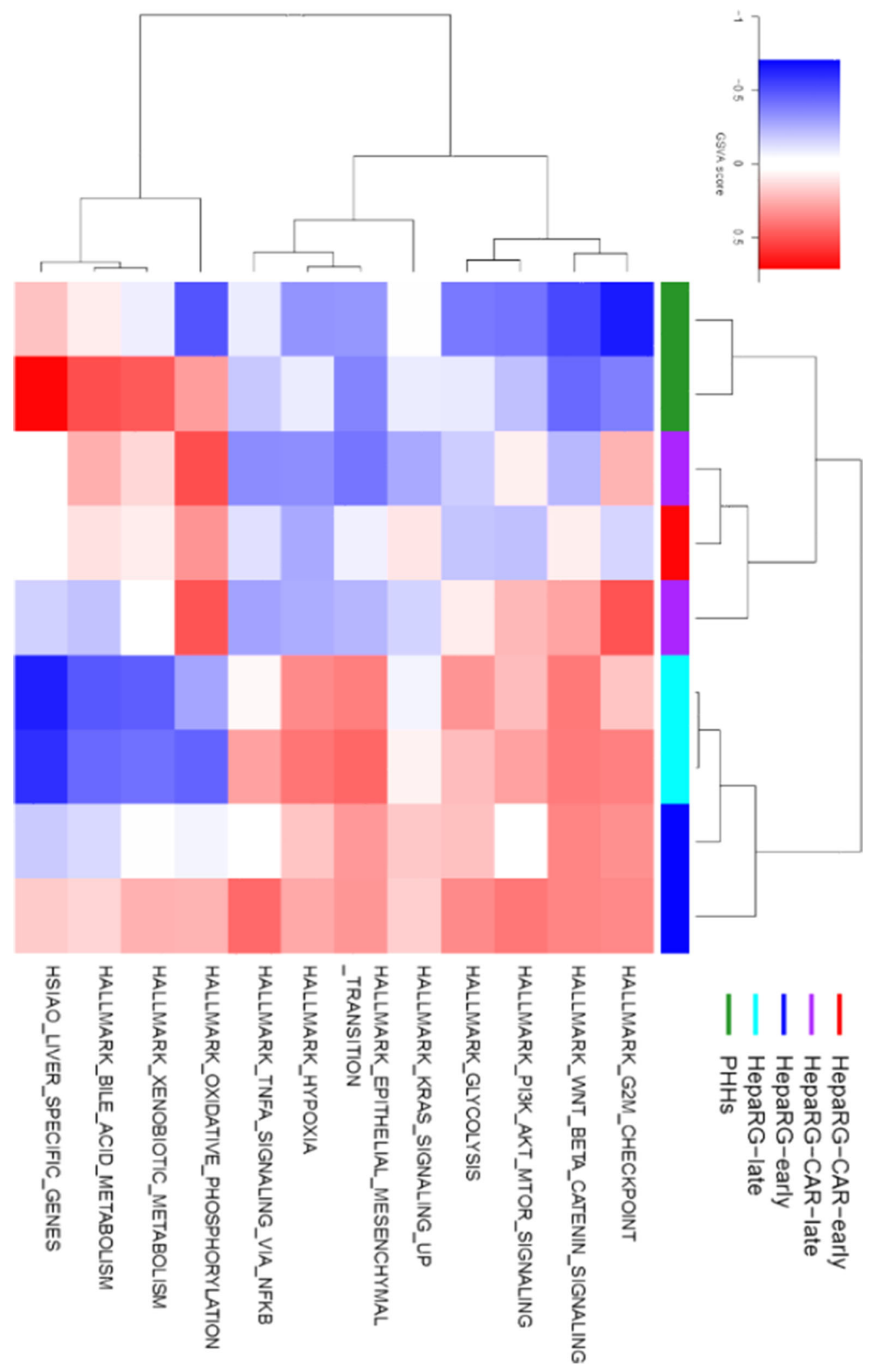


4 Fig. 3 Upon passaging, the transcriptional profile of HepaRG cells shifts towards dedifferentiation and cell proliferation with enhanced glycolysis. Heatmap of the sample-specific geneset enrichment scores determined by CAMERA analysis on selected genesets from top altered (FDR $<0.1)$ Hallmark genesets and the HSIAO liver-specific geneset of different comparisons. (Color figure online)

nutrient supply (Folkman 1971; Nishida 2005; Nishida et al. 2006), was downregulated upon the passaging of HepaRG-CAR cells. These results are pointing to a more stable hepatic and energy metabolic profile of HepaRG-CAR cells upon passaging compared to HepaRG cells, in line with the functional data.

The heatmap (Fig. 3, Online Resource 7), confirms the general picture of a sustained stability of HepaRGCAR cells upon passaging, in contrast to the parental HepaRG cells, where passaging exerted alterations in favor of loss of differentiation and epithelial-mesenchymal transition. In agreement with the PCA analysis (Fig. 2), the heatmap showed a clear clustering of the HepaRG-CAR cells (regardless of passaging) and the HepaRG early-passage, whereas the HepaRG late-passage cells clustered separately. Furthermore, CAR overexpression shifted the transcriptional profile of HepaRG cells from glycolysis towards mitochondrial energy metabolism, however, the effect on hepatic differentiation at transcript level seems low, resulting in a considerable gap in hepatic differentiation between HepaRG \pm CAR cells and PHHs.

In contrast to HepaRG, HepaRG-CAR cells produce less ROS

Oxidative stress is a driving force in aging processes, as well as diverse liver pathologies (Davalli et al. 2016; Kong et al. 2014). Oxidative stress reflects the balance between the generation of ROS, as byproduct of aerobic energy metabolism and the antioxidant system which detoxifies these reactive molecules (Lee et al. 2012; Li et al. 2015; Godoy et al. 2015). Important enzymes involved in ROS detoxification

Table 3 Top differentially regulated genesets in HepaRG early-passage vs. HepaRG-CAR early-passage

\begin{tabular}{lccc}
\hline Gene set & N genes & Direction & FDR \\
\hline HALLMARK_MYC_TARGETS_V1 & 197 & $\mathrm{Up}$ & $2.41 \mathrm{E}-07$ \\
HALLMARK_E2F_TARGETS & 199 & $\mathrm{Up}$ & $6.73 \mathrm{E}-06$ \\
HALLMARK_HYPOXIA & 198 & $\mathrm{Up}$ & $1.74 \mathrm{E}-05$ \\
HALLMARK_G2M_CHECKPOINT & 198 & $\mathrm{Up}$ & $2.39 \mathrm{E}-05$ \\
HALLMARK_EPITHELIAL_MESENCHYMAL_TRANSITION & 197 & $\mathrm{Up}$ & $7.26 \mathrm{E}-05$ \\
HALLMARK_GLYCOLYSIS & 198 & $\mathrm{Up}$ & $1.54 \mathrm{E}-03$ \\
HALLMARK_TNFA_SIGNALING_VIA_NFKB & 197 & $\mathrm{Up}$ & $4.08 \mathrm{E}-03$ \\
HALLMARK_MTORC1_SIGNALING & 199 & $\mathrm{Up}$ & $7.45 \mathrm{E}-03$ \\
HALLMARK_ALLOGRAFT_REJECTION & 187 & $\mathrm{Up}$ & $1.08 \mathrm{E}-02$ \\
HALLMARK_INFLAMMATORY_RESPONSE & 193 & $\mathrm{Up}$ & $1.46 \mathrm{E}-02$ \\
HALLMARK_OXIDATIVE_PHOSPHORYLATION & 199 & $\mathrm{Down}$ & $2.72 \mathrm{E}-02$ \\
HALLMARK_APOPTOSIS & 157 & $\mathrm{Up}$ & $3.10 \mathrm{E}-02$ \\
HALLMARK_UNFOLDED_PROTEIN_RESPONSE & 113 & $\mathrm{Up}$ & $3.31 \mathrm{E}-02$ \\
HALLMARK_DNA_REPAIR & 147 & $\mathrm{Up}$ & $3.36 \mathrm{E}-02$ \\
HALLMARK_PI3K_AKT_MTOR_SIGNALING & 104 & $\mathrm{Up}$ & $4.11 \mathrm{E}-02$ \\
HALLMARK_UV_RESPONSE_DN & 143 & $\mathrm{Up}$ & $5.14 \mathrm{E}-02$ \\
HALLMARK_TGF_BETA_SIGNALING & 53 & $\mathrm{Up}$ & $5.20 \mathrm{E}-02$ \\
HALLMARK_INTERFERON_GAMMA_RESPONSE & 195 & $\mathrm{Up}$ & $6.54 \mathrm{E}-02$ \\
HALLMARK_UV_RESPONSE_UP & 153 & $\mathrm{Up}$ & $9.93 \mathrm{E}-02$ \\
\hline
\end{tabular}

For the complete CAMERA analysis of the differential gene-set expression refer to Online Resource 2 
Table 4 Top 20 differentially regulated genesets in HepaRG early-passage vs. PHHs

\begin{tabular}{lcll}
\hline Gene set & N genes & Direction & FDR \\
\hline HSIAO_LIVER_SPECIFIC_GENES & 238 & Down & $1.46 \mathrm{E}-27$ \\
HALLMARK_MYC_TARGETS_V1 & 197 & $\mathrm{Up}$ & $1.03 \mathrm{E}-13$ \\
HALLMARK_E2F_TARGETS & 199 & $\mathrm{Up}$ & $1.68 \mathrm{E}-13$ \\
HALLMARK_G2M_CHECKPOINT & 198 & $\mathrm{Up}$ & $1.83 \mathrm{E}-12$ \\
HALLMARK_MITOTIC_SPINDLE & 198 & $\mathrm{Up}$ & $3.14 \mathrm{E}-06$ \\
HALLMARK_XENOBIOTIC_METABOLISM & 197 & $\mathrm{Down}$ & $5.69 \mathrm{E}-06$ \\
HALLMARK_BILE_ACID_METABOLISM & 111 & $\mathrm{Down}$ & $7.27 \mathrm{E}-06$ \\
HALLMARK_DNA_REPAIR & 147 & $\mathrm{Up}$ & $4.91 \mathrm{E}-05$ \\
HALLMARK_MYC_TARGETS_V2 & 58 & $\mathrm{Up}$ & $1.09 \mathrm{E}-04$ \\
HALLMARK_MTORC1_SIGNALING & 199 & $\mathrm{Up}$ & $1.43 \mathrm{E}-04$ \\
HALLMARK_P53_PATHWAY & 196 & $\mathrm{Up}$ & $1.82 \mathrm{E}-04$ \\
HALLMARK_PROTEIN_SECRETION & 96 & $\mathrm{Up}$ & $2.06 \mathrm{E}-04$ \\
HALLMARK_UNFOLDED_PROTEIN_RESPONSE & 113 & $\mathrm{Up}$ & $3.64 \mathrm{E}-04$ \\
HALLMARK_WNT_BETA_CATENIN_SIGNALING & 40 & $\mathrm{Up}$ & $5.33 \mathrm{E}-04$ \\
HALLMARK_APICAL_JUNCTION & 192 & $\mathrm{Up}$ & $5.48 \mathrm{E}-04$ \\
HALLMARK_EPITHELIAL_MESENCHYMAL_TRANSITION & 197 & $\mathrm{Up}$ & $6.09 \mathrm{E}-04$ \\
HALLMARK_COAGULATION & 131 & $\mathrm{Dpwn}$ & $8.11 \mathrm{E}-03$ \\
HALLMARK_GLYCOLYSIS & 198 & $\mathrm{Up}$ & $9.47 \mathrm{E}-03$ \\
HALLMARK_UV_RESPONSE_DN & 143 & $\mathrm{Up}$ & $1.10 \mathrm{E}-02$ \\
HALLMARK_FATTY_ACID_METABOLISM & 156 & Down & $1.15 \mathrm{E}-02$ \\
\hline H & &
\end{tabular}

For the complete CAMERA analysis of the differential gene-set expression refer to Online Resource 3

include superoxide dismutase (SOD) 1 and 2 and catalase (CAT) (Ghosh et al. 2013; Jones et al. 1993; Sea et al. 2015).

We tested whether the difference in stability between HepaRG and HepaRG-CAR may be associated with oxidative stress changes. Interestingly, the transcript levels of $C A T$ and $S O D 1$ were significantly higher in HepaRG-CAR vs. HepaRG cells at earlypassage, whereas SOD2 showed a positive trend (Fig. 4a). Furthermore, mitochondrial superoxide level was 2.0-fold lower in HepaRG-CAR vs. HepaRG cells (Fig. 4b), indicating that HepaRG-CAR cells are less exposed to ROS than HepaRG cells.

\section{Discussion}

There is an increasing demand for terminally-differentiated hepatocyte cultures to function as a hepatocyte-based in vitro model for human liver as well as biocomponent of BALs. The most functional proliferative source of human hepatocytes to date is the human liver cell line HepaRG, which shows a relatively broad spectrum of liver functions (Gripon et al. 2002; Hoekstra et al. 2011). In this study we demonstrate that, compared to the parental HepaRG cell line, the newly developed HepaRG-CAR cell line displays higher mitochondrial function, and, in part, higher hepatic differentiation, as well as increased stability upon passaging, and therefore outperforms the parental HepaRG cell line as proliferative source of human hepatocytes.

Previously it was established that HepaRG-CAR cells showed increased biotransformation, particularly at activity level, and albumin production compared to HepaRG cells (van der Mark et al. 2017). The current study additionally shows increased mitochondrial function, as reflected by lower lactate production, and also a higher bile acid production. Accordingly, the RNA-seq expression analysis confirmed the induction of OxPhos in HepaRG-CAR vs. HepaRG 
Table 5 Top 20 differentially regulated genesets in HepaRG-CAR early-passage vs. PHHs

\begin{tabular}{lcll}
\hline Gene set & N genes & Direction & FDR \\
\hline HSIAO_LIVER_SPECIFIC_GENES & 238 & Down & $3.87 \mathrm{E}-28$ \\
HALLMARK_G2M_CHECKPOINT & 198 & $\mathrm{Up}$ & $5.40 \mathrm{E}-10$ \\
HALLMARK_E2F_TARGETS & 199 & $\mathrm{Up}$ & $6.56 \mathrm{E}-10$ \\
HALLMARK_MYC_TARGETS_V1 & 197 & $\mathrm{Up}$ & $1.76 \mathrm{E}-08$ \\
HALLMARK_XENOBIOTIC_METABOLISM & 197 & Down & $5.79 \mathrm{E}-06$ \\
HALLMARK_MITOTIC_SPINDLE & 198 & $\mathrm{Up}$ & $1.15 \mathrm{E}-05$ \\
HALLMARK_BILE_ACID_METABOLISM & 111 & $\mathrm{Down}$ & $2.91 \mathrm{E}-05$ \\
HALLMARK_P53_PATHWAY & 196 & $\mathrm{Up}$ & $1.45 \mathrm{E}-03$ \\
HALLMARK_DNA_REPAIR & 147 & $\mathrm{Up}$ & $1.56 \mathrm{E}-03$ \\
HALLMARK_WNT_BETA_CATENIN_SIGNALING & 40 & $\mathrm{Up}$ & $1.84 \mathrm{E}-03$ \\
HALLMARK_MYC_TARGETS_V2 & 58 & $\mathrm{Up}$ & $1.87 \mathrm{E}-03$ \\
HALLMARK_COAGULATION & 131 & $\mathrm{Down}$ & $3.28 \mathrm{E}-03$ \\
HALLMARK_PROTEIN_SECRETION & 96 & $\mathrm{Up}$ & $3.50 \mathrm{E}-03$ \\
HALLMARK_APICAL_JUNCTION & 192 & $\mathrm{Up}$ & $4.81 \mathrm{E}-03$ \\
HALLMARK_MTORC1_SIGNALING & 199 & $\mathrm{Up}$ & $8.29 \mathrm{E}-03$ \\
HALLMARK_FATTY_ACID_METABOLISM & 156 & Down & $1.12 \mathrm{E}-02$ \\
HALLMARK_UNFOLDED_PROTEIN_RESPONSE & 113 & $\mathrm{Up}$ & $1.51 \mathrm{E}-02$ \\
HALLMARK_EPITHELIAL_MESENCHYMAL_TRANSITION & 197 & $\mathrm{Up}$ & $1.63 \mathrm{E}-02$ \\
HALLMARK_ANGIOGENESIS & 35 & $\mathrm{Up}$ & $1.83 \mathrm{E}-02$ \\
HALLMARK_OXIDATIVE_PHOSPHORYLATION & 199 & $\mathrm{Up}$ & $5.15 \mathrm{E}-02$ \\
\hline
\end{tabular}

For the complete CAMERA analysis of the differential gene-set expression refer to Online Resource 4

cells whereas glycolysis, hypoxia and proliferation processes were downregulated.

CAR is implicated not only in biotransformation through regulating the transcript level of a large array of genes involved in biotransformation, however, it also is involved, among others, in bile acid synthesis and in energy homeostasis by governing lipogenesis and gluconeogenesis (Bechmann et al. 2012; Chiang 2009; Cui and Klaassen 2016). The upregulation of bile acid synthesis is in line with our previous findings that several CYP enzymes are induced at transcript and/or activity level in HepaRG-CAR cells (van der Mark et al. 2017), as CYP enzymes are involved in the synthesis of bile acids from cholesterol (Cui and Klaassen 2016; Petrick and Klaassen 2007; Blazquez et al. 2013).

Several other studies suggested CAR as a critical transcription factor for regulating hepatocyte differentiation. CAR forms a transcriptional regulatory network with other nuclear receptors that are involved in hepatic differentiation, as hepatic nuclear factors 1 and 4 (Chen et al. 2018). Chen et al. demonstrated that lentiviral CAR-overexpression promotes the differentiation and maturation of human embryonic stem cells into hepatocyte-like cells (Chen et al. 2013). CAR further stimulates hepatic differentiation indirectly by promoting the synthesis of bile acids which, on their turn, activate the farnesoid $\mathrm{X}$ receptor and small heterodimer partner (FXR/SHP) signaling axis (Chiang 2013, 2017; Hoeke et al. 2014). Godoy et al. indicated FXR, CAR, pregnane $\mathrm{X}$ receptor and hepatic nuclear factor 1 as key transcription factors of a cluster of hepatic genes with low, deregulated, expression levels in stem cell-derived hepatocyte like cells and dedifferentiated PHHs relative to fully differentiated PHHs (Godoy et al. 2015, 2016). The genes overrepresented in this cluster were involved in biotransformation processes, most often CYPs (Godoy et al. 2015). These findings were confirmed by proteomic analyses showing that $\mathrm{PHH}$ dedifferentiation is particularly associated with changes in CYP levels (Heslop et al. 2017). Interestingly, the other group of 
Table 6 Top differentially regulated genesets (16 genesets) in HepaRG late-passage vs. HepaRG early-passage

\begin{tabular}{|c|c|c|c|}
\hline Gene set & $\mathrm{N}$ genes & Direction & FDR \\
\hline HSIAO_LIVER_SPECIFIC_GENES & 238 & Down & $1.52 \mathrm{E}-22$ \\
\hline HALLMARK_XENOBIOTIC_METABOLISM & 197 & Down & $1.63 \mathrm{E}-08$ \\
\hline HALLMARK_FATTY_ACID_METABOLISM & 156 & Down & $3.72 \mathrm{E}-07$ \\
\hline HALLMARK_BILE_ACID_METABOLISM & 111 & Down & $3.12 \mathrm{E}-06$ \\
\hline HALLMARK_INTERFERON_ALPHA_RESPONSE & 96 & Down & $3.82 \mathrm{E}-06$ \\
\hline HALLMARK_INTERFERON_GAMMA_RESPONSE & 195 & Down & $2.12 \mathrm{E}-05$ \\
\hline HALLMARK_HYPOXIA & 198 & Up & $2.38 \mathrm{E}-05$ \\
\hline HALLMARK_OXIDATIVE_PHOSPHORYLATION & 199 & Down & $4.48 \mathrm{E}-05$ \\
\hline HALLMARK_ADIPOGENESIS & 194 & Down & $1.49 \mathrm{E}-03$ \\
\hline HALLMARK_EPITHELIAL_MESENCHYMAL_TRANSITION & 197 & Up & $8.09 \mathrm{E}-03$ \\
\hline HALLMARK_MYC_TARGETS_V1 & 197 & Up & $1.25 \mathrm{E}-02$ \\
\hline HALLMARK_REACTIVE_OXIGEN_SPECIES_PATHWAY & 47 & Down & $1.70 \mathrm{E}-02$ \\
\hline HALLMARK_COAGULATION & 131 & Down & $1.73 \mathrm{E}-02$ \\
\hline HALLMARK_PEROXISOME & 101 & Down & $1.80 \mathrm{E}-02$ \\
\hline HALLMARK_DNA_REPAIR & 147 & Up & $2.08 \mathrm{E}-02$ \\
\hline HALLMARK_P53_PATHWAY & 196 & Up & $3.43 \mathrm{E}-02$ \\
\hline
\end{tabular}

For the complete CAMERA analysis of the differential gene-set expression refer to Online Resource 5

Table 7 Top differentially regulated genesets (8 genesets) in HepaRG-CAR late-passage vs. HepaRG-CAR early-passage

\begin{tabular}{|c|c|c|c|}
\hline Gene set & $\mathrm{N}$ genes & Direction & FDR \\
\hline HALLMARK_MYC_TARGETS_V1 & 197 & Up & $1.02 \mathrm{E}-08$ \\
\hline HALLMARK_E2F_TARGETS & 199 & Up & $1.20 \mathrm{E}-08$ \\
\hline HALLMARK_G2M_CHECKPOINT & 198 & Up & $1.52 \mathrm{E}-05$ \\
\hline HALLMARK_DNA_REPAIR & 147 & Up & $1.54 \mathrm{E}-05$ \\
\hline HALLMARK_MYC_TARGETS_V2 & 58 & Up & $3.45 \mathrm{E}-03$ \\
\hline HALLMARK_EPITHELIAL_MESENCHYMAL_TRANSITION & 197 & Down & $6.31 \mathrm{E}-02$ \\
\hline HALLMARK_ANGIOGENESIS & 35 & Down & $9.23 \mathrm{E}-02$ \\
\hline HALLMARK_MTORC1_SIGNALING & 199 & Up & $9.55 \mathrm{E}-02$ \\
\hline
\end{tabular}

For the complete CAMERA analysis of the differential gene-set expression refer to Online Resource 6

proteins associated with $\mathrm{PHH}$ dedifferentiation comprised of mitochondrial proteins. This is in agreement with a large-scale transcriptomic and proteomic study, which reported that early changes associated with hepatic dedifferentiation related, in part, to inhibition of major metabolic pathways taking place in the mitochondria, such as TCA cycle, $\beta$-oxidation of fatty acids and oxidative phosphorylation (Lauschke et al. 2016). Both CYPs and energy metabolism are, at least partly, under transcriptional control of CAR, therefore it is likely that CAR upregulation will inhibit the dedifferentiation of PHHs.

The mechanistic processes downstream of CAR in regulating energy homeostasis are still under investigation. These studies are complicated by speciesspecific differences between rodent and human CAR for their gene targets and mode of activity (Niu et al. 2018; Yang et al. 2014). Highly intriguing, however, is the new finding that the signaling of the mammalian target of rapamycin complex 1 (mTORC1) is 


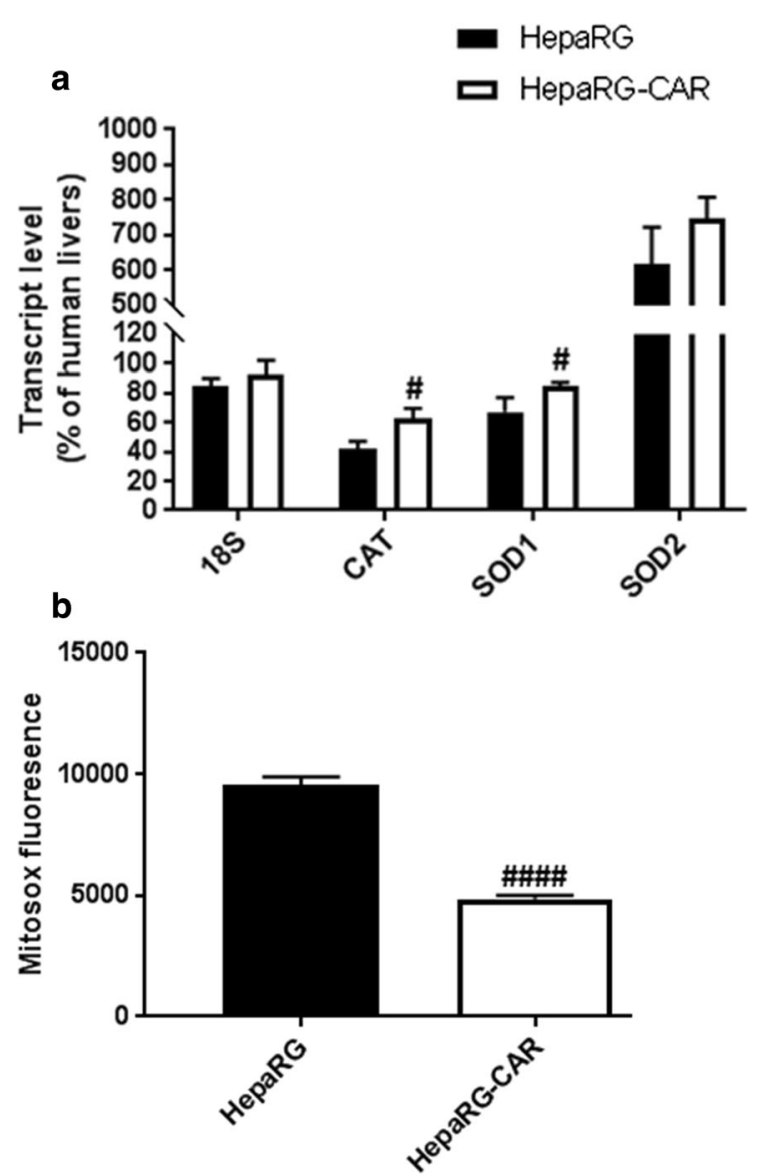

Fig. 4 HepaRG-CAR cells produce less ROS. a The transcript levels of antioxidant genes expressed as a \% of human livers. Also shown is the level of $18 S$ ribosomal RNA, which was not changed in HepaRG-CAR line vs. HepaRG cells and was comparable to human liver level, and was used as reference gene for normalization of the RT-qPCR data (Bustin et al. 2009). b ROS production $(n=4 / 2$ exp). Data was represented as mean $\pm \mathrm{SD} ; P$-value $<0.05$ was considered as significant

downregulated in HepaRG-CAR vs. HepaRG cells, as well as the Myc target genesets (Table 2). The mTORC1 complex is a nutrient sensor that, through activation of c-myc, drives cancer progression and metabolic reprogramming, characterized by upregulation of glycolysis, despite the presence of sufficient oxygen, and simultaneously limiting OxPhos, a phenomenon known as the Warburg effect (Harachi et al. 2018; Vander Heiden et al. 2009; Warburg 1956). In line with this, our study shows that CAR overexpression is associated with the reversion of the Warburg effect in HepaRG cells, with downregulation of glycolysis and upregulation of OxPhos genesets, which may be mediated by the mTORC1 pathway through c-myc. Interestingly, Parent et al. showed that sustained mTOR activity induced a preneoplastic phenotype to HepaRG cells by altering the translation of genes vital for establishing normal hepatic energy homeostasis and moderating hepatocellular growth (Parent et al. 2007). Moreover, these neoplastic changes were reversible upon administration of the classic mTORC1 inhibitor rapamycin.

In parallel, mTORC1 signalling and c-myc, being well-known for their tumor-promoting effects, may play an important role in the transformation of HepaRG cells normally occurring at P20, and characterized by morphological changes, decreased ammonia elimination and bile acid synthesis and increased lactate production, which is inhibited in HepaRGCAR cells. Changes in expression profile associated with the transformation in HepaRG cells included downregulation of genesets associated with hepatic functions and induction of epithelial mesenchymal transition and hypoxia. Moreover, several cell proliferation related genesets were induced, further confirming the epithelial mesenchymal transition. These manifestations, also described in (Heslop et al. 2017; Niu et al. 2018), as associated with the dedifferentiation of PHHs in culture, are characteristic for the Warburg effect (Vander Heiden et al. 2009; Warburg 1956).

Thus far, there are no studies about the mechanism governing the dedifferentiation process in HepaRG cells. However, several studies demonstrated the involvement of oxidative stress in pathological mechanisms of a vast range of liver pathologies ( $\mathrm{Li}$ et al. 2015), as well as mitochondrial dysfunction and the Warburg effect (Vander Heiden et al. 2009; Warburg 1956). Oxidative stress is caused by high levels of ROS, the net result of production through oxidative phosphorylation and scavenging by antioxidant activity. The production of ROS may be increased in HepaRG-CAR cells, due to its increased mitochondrial energy metabolism. However, and possibly due to the induction of antioxidant enzymes, the net amount of ROS was reduced to $50 \%$ of the level of HepaRG cells. Given the pronounced effect on ROS production and the relatively limited upregulation of SOD1 and CAT mRNA, posttranslational modifications of these antioxidant enzymes or other antioxidant systems may also be involved (Cao et al. 2003; Glorieux et al. 2015; Miao and St Clair 2009). The relatively low ROS levels may, at least, partly attribute 
to HepaRG-CAR cells long-term stability. This finding seems in conflict with the downregulation of the ROS-related geneset in HepaRG cells late vs. earlypassage, which was accompanied by the drastic loss of mitochondrial energy metabolism as shown by the suppression of genesets related to OxPhos and fatty acid metabolism and the increased production of lactate. The level and role of ROS may be dynamically regulated during passaging and may differ for both cell lines, which needs to be further analyzed. In addition, the role of mTORC1 signaling should be further analyzed. mTORC1 may play an essential role in the transformation of HepaRG cells, as inhibition of mTORC1 has been shown to delay age-related diseases, due to stimulation of autophagy and possibly modulation of immune responses (Meijer and Codogno 2007; Weichhart 2018).

The transcriptional profile of HepaRG cells earlypassage was dissimilar from that of the PHHs, in line with our previous study (Adam et al. 2018b). The transcriptional profile of HepaRG-CAR cells, regardless of the passage number, clustered closely with HepaRG cells at early-passage and differed from that of PHHs. Interestingly, the cellular bioenergetics of HepaRG-CAR cells (regardless of passage number) was shifted towards the PHHs profile with the induction of OxPhos and inhibition of hypoxia and glycolysis Hallmark genesets. Yet, when related to PHHs, xenobiotic detoxification, bile acid metabolism and HSIAO liver specific-geneset were downregulated in HepaRG-CAR cells, indicating that there is still room for further improvement to advance their hepatic differentiation. However, the relatively high heterogeneity in the transcriptional profile of the $\mathrm{PHH}$ replicates, complicates the interpretation of the transcriptional data in relation to PHHs. This may be, in part, related to the optional dedifferentiation of the PHHs that involves down-regulation of important liver-enriched transcription factors and subsequently loss of hepatic differentiation (Elaut et al. 2006). It is widely believed that the dedifferentiation process is initiated, as early as, during hepatocyte isolation phase and it progressively continues during their in vitro cultivation (Elaut et al. 2006; Godoy et al. 2009; Zellmer et al. 2010). To limit misinterpretation of transcriptional data, due to this optional PHH dedifferentiation, we used isolated PHHs without in vitro cultivation as reference materials. The PCA analysis of the full transcriptome showed that the differences between the two $\mathrm{PHH}$ isolates were relatively small compared to differences between cell lines and differences within HepaRG cultures over time. However, the PHH replicates displayed substantial variations in their transcriptional profile for specific genesets, particularly for those related to OxPhos and liver-related functions, which may be related to biological variation between patients. The observed upregulation of hepatic functions, including albumin and bile acid synthesis, as well as a range of biotransformation activities in HepaRG-CAR cells vs. HepaRG cells (van der Mark et al. 2017), seems in conflict with the lack of upregulated genesets associated with hepatic differentiation in the transcriptome analysis. This suggests that the effects of CAR overexpression most probably are mediated at posttranscriptional level. The shift in energy metabolism by CAR overexpression may modulate hepatic functions due to alteration in metabolite spectrum that governs the flux rates of many metabolic pathways (Madiraju et al. 2016) and to increased fluxes of energy-consuming processes, such as biotransformation. Moreover, the accumulation of metabolites normally eliminated by the mitochondria, such as lactate, will be inhibited, which may improve hepatic functionality (Catapano et al. 1996). Furthermore, CAR overexpression enhances the mRNA expression of CYP450 oxidoreductase (POR) (van der Mark et al. 2017), which mediates the electron transfer required for P450 activity (Gutierrez et al. 2003). Therefore, the upregulation of POR may contribute at posttranscriptional level to the increased biotransformation activity of HepaRG-CAR. It will be, however, difficult to distinguish between the different players that may post-transcriptionally increase the hepatic functionality of HepaRG cells upon CAR overexpression, due to interconnections between the processes regulated by the concentration of metabolites and energy derivatives.

\section{Conclusions}

Given the advanced biotransformation properties, mitochondrial functions and the sustained stability, this work demonstrates that, the newly-developed HepaRG-CAR cell line is more suitable as an attractive alternative to PHHs for BAL application and for in vitro drug toxicity studies. For the support of 
patients with end-stage liver failure it is estimated that a functional liver mass of $150 \mathrm{~g}\left(15 \times 10^{9}\right.$ cells $)$ is required (Tsiaoussis et al. 2001). This implies that at least 11 passages from the first single HepaRG cell are needed to load a single BAL. Therefore, the extended stability of the HepaRG-CAR cells upon passaging is essential for BAL application. Other applications requiring human liver cells, as pre-clinical studies in drug development and research on liver functions and infections, require substantial less cells, however, also for those applications, the highest hepatic functionality is required, and therefore also in those cases the HepaRG-CAR cells are the best available alternative to PHHs.

Acknowledgements The authors would like to thank Erik Hendriks for cell culturing.

Funding The project is financed by the Dutch Ministry of Economic Affairs and Climate Policy by means of the PPP Allowance made available by the Top Sector Life Sciences \& Health to stimulate public-private partnerships, and by the Netherlands Organization for Health Research and Development, More Knowledge with Fewer Animals, Grant 114021009 (ZonMw). The project is also financed by two companies: Biopredic International, France, and Hep-Art Medical Devices B.V., the Netherlands.

\section{Compliance with ethical standards}

Conflict of interest/financial support Robert Chamuleau is Chief Scientific Officer of the university spin-off company HepArt Medical Devices B.V that holds the exclusive license to the AMC-Bioartificial liver. All other authors have no other relevant affiliations or financial involvement with any organization or entity with a financial interest in or financial conflict with the subject matter or materials discussed in the manuscript apart from those disclosed.

Open Access This article is licensed under a Creative Commons Attribution 4.0 International License, which permits use, sharing, adaptation, distribution and reproduction in any medium or format, as long as you give appropriate credit to the original author(s) and the source, provide a link to the Creative Commons licence, and indicate if changes were made. The images or other third party material in this article are included in the article's Creative Commons licence, unless indicated otherwise in a credit line to the material. If material is not included in the article's Creative Commons licence and your intended use is not permitted by statutory regulation or exceeds the permitted use, you will need to obtain permission directly from the copyright holder. To view a copy of this licence, visit http://creativecommons.org/licenses/by/4.0/.

\section{References}

Adam AAA, van der Mark VA, Donkers JM, Wildenberg ME, Oude Elferink RPJ, Chamuleau R, Hoekstra R (2018a) A practice-changing culture method relying on shaking substantially increases mitochondrial energy metabolism and functionality of human liver cell lines. PLoS ONE 13:e0193664

Adam AAA, van Wenum M, van der Mark VA, Jongejan A, Moerland PD, Houtkooper RH, Wanders RJA, Elferink ROude, Chamuleau RPJ, Hoekstra R (2018b) AMC-BioArtificial Liver culturing enhances mitochondrial biogenesis in human liver cell lines: the role of oxygen, medium perfusion and 3d configuration. Mitochondrion 39:30-42

Andersson TB, Kanebratt KP, Kenna JG (2012) The HepaRG cell line: a unique in vitro tool for understanding drug metabolism and toxicology in human. Expert Opin Drug Metab Toxicol 8:909-920

Bairoch A (2018) The cellosaurus, a cell-line knowledge resource. J Biomol Tech 29:25-38

Bechmann LP, Hannivoort RA, Gerken G, Hotamisligil GS, Trauner M, Canbay A (2012) The interaction of hepatic lipid and glucose metabolism in liver diseases. J Hepatol 56:952-964

Bell CC, Lauschke VM, Vorrink SU, Palmgren H, Duffin R, Andersson T, Ingelman-Sundberg M (2017) Transcriptional, functional, and mechanistic comparisons of stem cell-derived hepatocytes, HepaRG cells, and three-dimensional human hepatocyte spheroids as predictive in vitro systems for drug-induced liver injury. Drug Metab Dispos 45:419-429

Blazquez MA, Carretero A, Ellis JK, Athersuch TJ, Cavill R, Ebbels TM, Kuen HC, Castell JV, Lahoz A, Bort R (2013) A combination of transcriptomics and metabolomics uncovers enhanced bile acid biosynthesis in HepG2 cells expressing CCAAT/enhancer-binding protein beta $(\mathrm{C} /$ EBPbeta), hepatocyte nuclear factor 4alpha (HNF4alpha), and constitutive androstane receptor (CAR). J Proteome Res 12:2732-2741

Bols NC, Pham PH, Dayeh VR, Lee LEJ (2017) Invitromatics, invitrome, and invitroomics: introduction of three new terms for in vitro biology and illustration of their use with the cell lines from rainbow trout. In Vitro Cell Dev Biol Anim 53:383-405

Bustin SA, Benes V, Garson JA, Hellemans J, Huggett J, Kubista M, Mueller R, Nolan T, Pfaffl MW, Shipley GL, Vandesompeley J, Wittwer CT (2009) The MIQE guidelines: minimum information for publication of quantitative real-time PCR experiments. Clin Chem 55:611-622

Cao C. Leng Y, Kufe D (2003) Catalase activity is regulated by $\mathrm{c}-\mathrm{Abl}$ and $\mathrm{Arg}$ in the oxidative stress response. J Biol Chem 278:29667-29675

Catapano G, De Bartolo L, Lombardi CP, Drioli E (1996) The effect of catabolite concentration on the viability and functions of isolated rat hepatocytes. Int J Artif Organs 19:245-250

Chen F, Zamule SM, Coslo DM, Chen T, Omiecinski CJ (2013) The human constitutive androstane receptor promotes the differentiation and maturation of hepatic-like cells. Dev Biol 384:155-165 
Chen L, Bao Y, Piekos SC, Zhu K, Zhang L, Zhong XB (2018) A transcriptional regulatory network containing nuclear receptors and long noncoding RNAs controls basal and drug-induced expression of Cytochrome P450s in HepaRG cells. Mol Pharmacol 94:749-759

Chiang JY (2009) Bile acids: regulation of synthesis. J Lipid Res 50:1955-1966

Chiang JY (2013) Bile acid metabolism and signaling. Compr Physiol 3:1191-1212

Chiang JYL (2017) Bile acid metabolism and signaling in liver disease and therapy. Liver Res 1:3-9

Cui JY, Klaassen CD (2016) RNA-seq reveals common and unique PXR- and CAR-target gene signatures in the mouse liver transcriptome. Biochim Biophys Acta 1859:1198-1217

Davalli P, Mitic T, Caporali A, Lauriola A, D’Arca D (2016) ROS, cell senescence, and novel molecular mechanisms in aging and age-related diseases. Oxid Med Cell Longev 2016:3565127

Elaut G, Henkens T, Papeleu P, Snykers S, Vinken M, Vanhaecke T, Rogiers V (2006) Molecular mechanisms underlying the dedifferentiation process of isolated hepatocytes and their cultures. Curr Drug Metab 7:629-660

Folkman J (1971) Tumor angiogenesis: therapeutic implications. N Engl J Med 285:1182-1186

Gao X, Liu Y (2017) A transcriptomic study suggesting human iPSC-derived hepatocytes potentially offer a better in vitro model of hepatotoxicity than most hepatoma cell lines. Cell Biol Toxicol 33:407-421

Ghosh S, Willard B, Comhair SA, Dibello P, Xu W, Shiva S, Aulak KS, Kinter M, Erzuruml SC (2013) Disulfide bond as a switch for copper-zinc superoxide dismutase activity in asthma. Antioxid Redox Signal 18:412-423

Glorieux C, Zamocky M, Sandoval JM, Verrax J, Calderon PB (2015) Regulation of catalase expression in healthy and cancerous cells. Free Radic Biol Med 87:84-97

Godoy P, Hengstler JG, Ilkavets I, Meyer C, Bachmann A, Muller A, Tuschl G, Mueller SO, Dooley S (2009) Extracellular matrix modulates sensitivity of hepatocytes to fibroblastoid dedifferentiation and transforming growth factor beta-induced apoptosis. Hepatology 49:2031-2043

Godoy P, Schmidt-Heck W, Natarajan K, Lucendo-Villarin B, Szkolnicka D, Asplund A, Bjorquist P, Widera A, Stober R, Campos G, Hammad S, Sachinidis A, Chaudhari U, Damm G, Weiss TS, Nussler A, Synnergren J, Edlund K, KuppersMunther B, Hay DC, Hengstler JG (2015) Gene networks and transcription factor motifs defining the differentiation of stem cells into hepatocyte-like cells. J Hepatol 63:934-942

Godoy P, Widera A, Schmidt-Heck W, Campos G, Meyer C, Cadenas C, Reif R, Stöber R, Hammad S, Pütter L, Gianmoena K, Marchan R, Ghallab A, Edlund K, Nüssler A, Thasler WE, Damm G, Seehofer D, Weiss TS, Dirsch O, Dahmen U, Gebhardt R, Chaudhari U, Meganathan K, Sachinidis A, Kelm J, Hofmann U, Zahedi RP, Guthke R, Blüthgen N, Dooley S, Hengstler JG (2016) Gene network activity in cultivated primary hepatocytes is highly similar to diseased mammalian liver tissue. Arch Toxicol 90:2513-2529

Gripon P, Rumin S, Urban S, Le Seyec J, Glaise D, Cannie I, Guyomard C, Lucas J, Trepo C, Guguen-Guillouzo C
(2002) Infection of a human hepatoma cell line by hepatitis B virus. Proc Natl Acad Sci USA 99:15655-15660

Gutierrez A, Grunau A, Paine M, Munro AW, Wolf CR, Roberts GC, Scrutton NS (2003) Electron transfer in human Cytochrome $\mathrm{P} 450$ reductase. Biochem Soc Trans 31:497-501

Harachi M, Masui K, Okamura Y, Tsukui R, Mischel PS, Shibata N (2018) MTOR complexes as a nutrient sensor for driving cancer progression. Int J Mol Sci 19:3276

Heslop JA, Rowe C, Walsh J, Sison-Young R, Jenkins R, Kamalian L, Kia R, Hay D, Jones RP, Malik HZ, Fenwick S, Chadwick AE, Mills J, Kitteringham NR, Goldring CE, Kevin Park B (2017) Mechanistic evaluation of primary human hepatocyte culture using global proteomic analysis reveals a selective dedifferentiation profile. Arch Toxicol 91:439-452

Hoeke MO, Heegsma J, Hoekstra M, Moshage H, Faber KN (2014) Human FXR regulates SHP expression through direct binding to an LRH-1 binding site, independent of an IR-1 and LRH-1. PLoS ONE 9:e88011

Hoekstra R, Deurholt T, Poyck PP, ten Bloemendaal L, Chhatta AA (2005) Increased reproducibility of quantitative reverse transcriptase-PCR. Anal Biochem 340:376-379

Hoekstra R, Deurholt T, ten Bloemendaal L, Desille M, van Wijk AC, Clement B, Oude Elferink RP, van Gulik TM, Chamuleau RA (2006) Assessment of in vitro applicability of reversibly immortalized NKNT-3 cells and clonal derivatives. Cell Transplant 15:423-433

Hoekstra R, Nibourg GA, van der Hoeven TV, Ackermans MT, Hakvoort TB, van Gulik TM, Lamers WH, Oude Elferink RP, Chamuleau RA (2011) The HepaRG cell line is suitable for bioartificial liver application. Int J Biochem Cell Biol 43:1483-1489

Hoekstra R, Nibourg GA, van der Hoeven TV, Plomer G, Seppen J, Ackermans MT, Camus S, Kulik W, van Gulik TM, Oude Elferink RPJ, Chamuleau RA (2013) Phase 1 and phase 2 drug metabolism and bile acid production of HepaRG cells in a bioartificial liver in absence of dimethyl sulfoxide. Drug Metab Dispos 41:562-577

Hsiao LL, Dangond F, Yoshida T, Hong R, Jensen RV, Misra J, Dillon W, Lee KF, Clark KE, Haverty P, Weng Z, Mutter GL, Frosch MP, MacDonald ME, Milford EL, Crum CP, Bueno R, Pratt RE, Mahadevappa M, Warrington JA, Stephanopoulos G, Stephanopoulos G, Gullans SR (2001) A compendium of gene expression in normal human tissues. Physiol Genomics 7:97-104

Jones CT, Brock DJ, Chancellor AM, Warlow CP, Swingler RJ (1993) $\mathrm{Cu} / \mathrm{Zn}$ superoxide dismutase (SOD1) mutations and sporadic amyotrophic lateral sclerosis. Lancet 342:1050-1051

Kong Y, Trabucco SE, Zhang H (2014) Oxidative stress, mitochondrial dysfunction and the mitochondria theory of aging. Interdiscip Top Gerontol 39:86-107

Kvist AJ, Kanebratt KP, Walentinsson A, Palmgren H, O'Hara M, Bjorkbom A, Andersson L, Ahlqvist LC, Andersson M TB (2018) Critical differences in drug metabolic properties of human hepatic cellular models, including primary human hepatocytes, stem cell derived hepatocytes, and hepatoma cell lines. Biochem Pharmacol 155:124-140

Laurent V, Glaise D, Nubel T, Gilot D, Corlu A, Loyer P (2013) Highly efficient siRNA and gene transfer into hepatocyte- 
like HepaRG cells and primary human hepatocytes: new means for drug metabolism and toxicity studies. Methods Mol Biol 987:295-314

Lauschke VM, Vorrink SU, Moro SML, Rezavee F, Nordling ^, Hendriks DFG, Bell CC, Sison-Young R, Park K, Goldring CE, Ellis E, Johansson I, Mkrtchian S, Andersson TB, Ingelman-Sundberg M (2016) Massive rearrangements of cellular microRNA signatures are key drivers of hepatocyte dedifferentiation. Hepatology 64:1743-1756

Lee J, Giordano S, Zhang J (2012) Autophagy, mitochondria and oxidative stress: cross-talk and redox signalling. Biochem J 441:523-540

Li S, Tan HY, Wang N, Zhang ZJ, Lao L, Wong CW, Feng Y (2015) The role of oxidative stress and antioxidants in liver diseases. Int J Mol Sci 16:26087-26124

Liberzon A, Birger C, Thorvaldsdottir H, Ghandi M, Mesirov JP, Tamayo P (2015) The molecular signatures database (MSigDB) hallmark gene set collection. Cell Syst 1:417-425

Madiraju AK, Alves T, Zhao X, Cline GW, Zhang D, Bhanot S, Samuel VT, Kibbey RG, Shulman GI (2016) Argininosuccinate synthetase regulates hepatic AMPK linking protein catabolism and ureagenesis to hepatic lipid metabolism. Proc Natl Acad Sci USA 113:E3423-E3430

Meijer AJ, Codogno P (2007) AMP-activated protein kinase and autophagy. Autophagy 3:238-2340

Miao L, St Clair DK (2009) Regulation of superoxide dismutase genes: implications in disease. Free Radic Biol Med 47:344-356

Nibourg GA, Chamuleau RA, van der Hoeven TV, Maas MA, Ruiter AF, Lamers WH, Oude Elferink RP, van Gulik TM, Hoekstra R (2012) Liver progenitor cell line HepaRG differentiated in a bioartificial liver effectively supplies liver support to rats with acute liver failure. PLoS ONE 7:e38778

Nibourg GA, Hoekstra R, van der Hoeven TV, Ackermans MT, Hakvoort TB, van Gulik TM, Chamuleau RA (2013) Increased hepatic functionality of the human hepatoma cell line HepaRG cultured in the AMC bioreactor. Int J Biochem Cell Biol 45:1860-1868

Nishida T (2005) Angiogenesis, which is essential for cancer growth, is a diagnostic and therapeutic target. J Gastroenterol 40:320-321

Nishida N, Yano H, Nishida T, Kamura T, Kojiro M (2006) Angiogenesis in cancer. Vasc Health Risk Manag 2:213-219

Niu B, Coslo DM, Bataille AR, Albert I, Pugh BF, Omiecinski CJ (2018) In vivo genome-wide binding interactions of mouse and human constitutive androstane receptors reveal novel gene targets. Nucleic Acids Res 46:8385-8403

Parent R, Kolippakkam D, Booth G, Beretta L (2007) Mammalian target of rapamycin activation impairs hepatocytic differentiation and targets genes moderating lipid homeostasis and hepatocellular growth. Cancer Res 67:4337-4345
Petrick JS, Klaassen CD (2007) Importance of hepatic induction of constitutive androstane receptor and other transcription factors that regulate xenobiotic metabolism and transport. Drug Metab Dispos 35:1806-1815

Sea K, Sohn SH, Durazo A, Sheng Y, Shaw BF, Cao X, Taylor AB, Whitson LJ, Holloway SP, Hart PJ, Cabelli DE, Gralla $\mathrm{EB}$, Valentine JS (2015) Insights into the role of the unusual disulfide bond in copper-zinc superoxide dismutase. J Biol Chem 290:2405-2418

Sison-Young RL, Lauschke VM, Johann E et al (2017) A multicenter assessment of single-cell models aligned to standard measures of cell health for prediction of acute hepatotoxicity. Arch Toxicol 91:1385-1400

Tsiaoussis J, Newsome PN, Nelson LJ, Hayes PC, Plevris JN (2001) Which hepatocyte will it be? Hepatocyte choice for bioartificial liver support systems. Liver Transpl 7:2-10

Van der Mark VA, de Waart DR, Shevchenko V, Oude Elferink RP, Chamuleau RA, Hoekstra R (2017) Stable overexpression of the constitutive androstane receptor reduces the requirement for culture with dimethyl sulfoxide for high drug metabolism in HepaRG cells. Drug Metab Dispos 45:56-67

Van Wenum M, Chamuleau RA, van Gulik TM, Siliakus A, Seppen J, Hoekstra R (2014) Bioartificial livers in vitro and in vivo: tailoring biocomponents to the expanding variety of applications. Expert Opin Biol Ther 14:1745-1760

Vander Heiden MG, Cantley LC, Thompson CB (2009) Understanding the Warburg effect: the metabolic requirements of cell proliferation. Science 324:1029-1033

Warburg O (1956) On the origin of cancer cells. Science 123:309-314

Weichhart T (2018) MTOR as regulator of lifespan, aging, and cellular senescence: a mini-review. Gerontology 64:127-134

Yan J, Chen B, Lu J, Xie W (2015) Deciphering the roles of the constitutive androstane receptor in energy metabolism. Acta Pharmacol Sin 36:62-70

Yang H, Garzel B, Heyward S, Moeller T, Shapiro P, Wang H (2014) Metformin represses drug-induced expression of CYP2B6 by modulating the constitutive androstane receptor signaling. Mol Pharmacol 85:249-260

Zellmer S, Schmidt-Heck W, Godoy P, Weng H, Meyer C, Lehmann T, Sparna T, Schormann W, Hammad S, Kreutz C, Timmer J, von Weizsacker F, Thurmann PA, Merfort I, Guthke R, Dooley S, Hengstler JG, Gebhardt R (2010) Transcription factors ETF, E2F, and SP-1 are involved in cytokine-independent proliferation of murine hepatocytes. Hepatol 52:2127-2136

Zhou R, Yazdi AS, Menu P, Tschopp J (2011) A role for mitochondria in NLRP3 inflammasome activation. Nature 469:221-225

Publisher's Note Springer Nature remains neutral with regard to jurisdictional claims in published maps and institutional affiliations. 